\title{
Commission 19: Rotation of the Earth
}

\author{
PRESIDENT: Veronique Dehant \\ VICE-PRESIDENT: Aleksander Brzezinski \\ ORGANIZING COMMITTEE (OC): N. Capitaine, J. Dickey, \\ T. Fukushima, D. Gambis, R. Gross, J. Hefty, C. Huang, C. Ma, \\ Z. Malkin, A. Poma, J. Ray, B. Richter, C. Ron, M. Rothacher \\ (IAG representative), N. Sidorenkov, M. Soffel, and J. Vondrak
}

\begin{abstract}
The activities in scientific research related to Commission 19 are mostly developed in the different institutions that have sent their reports here enclosed, in the different meetings that have been organized in related themes, and in the WGs of the Division 1. An important additional activity has been developed in the frame of precession and nutation. This research has been initiated by the Descartes Prize received by the Nutation Consortium in 2003.
\end{abstract}

\section{Terms of Reference of Commission 19}

The OC has prepared the following charter:

Commission 19 of the International Astronomical Union (IAU) is a part of the IAU Division I. The Commission is created to fulfill a specific scientific goals related to the Earth rotation, Earth orientation, and related reference frames.

The objectives of Commission 19 are:

(a) Encourage and develop cooperation and collaboration in observation and theoretical studies of Earth orientation (the motions of the pole in the terrestrial and celestial reference systems and the rotation about the pole).

(b) Serve the astronomical community by linking it to the official organizations providing the International Terrestrial and Celestial Reference Systems/Frames (ITRS and ITRF) and Earth orientation parameters: International Association of Geodesy (IAG), International Earth Rotation and Reference System Service (IERS), International VLBI Service for Geodesy and Astrometry (IVS), International GPS Service (IGS), International Laser Ranging Service (ILRS), International DORIS Service (IDS).

(c) Develop methods for improving the accuracy and understanding of Earth orientation and related reference systems/frames.

(d) Ensure agreement and continuity of the reference frames used for Earth orientation with other astronomical reference frames and their densification.

(e) Provide means of comparing observational and analysis methods and results to ensure accuracy of data and models.

The organization of Commission 19 is the following. The Commission consists of its members and consultants, and is chaired by the President. To coordinate its activity, the Commission forms the Organizing Committee (OC) (see above for its composition). The Organizing Committee includes ex-officio members (the past Commission President and representatives from the IAG, IERS, IVS, IGS, ILRS, and IDS) and members at large. Each IAU member who is interested in the participation in the Commission activity may be a member of the Commission. No election procedure for a membership is established; only recommendation from the Commission 19 OC is needed. 


\section{Scientific activities}

The activities in scientific research related to Commission 19 are mostly developed in the different institutions that have sent their reports here enclosed, in the different meetings that have been organized in related themes, and in the WGs of the Division 1. An important additional activity has been developed in the frame of precession and nutation. This research has been initiated by the Descartes Prize received by the Nutation Consortium in 2003. The money (300000) has been dedicated to young scientist proposals. A call for proposals has been sent out at the beginning of 2004 and 15 proposals have been selected for either PhD students or postdocs. Additionally, money has been dedicated to travel support for participation in meetings for disfavored countries. Furthermore, the activities of these last three years include

(a) Participation in special meetings related to Earth rotation, such as Journées Systèmes de Références Spatio-temporels in Paris, ECGS Chandler Wobble Workshop in Luxembourg (on 'Forcing of polar motion in the Chandler frequency band: a contribution to understanding inter-annual climate variations').

(b) Linking Commission 19 with its sister commission of the IAG, Commission 3 on 'Earth Rotation and Geodynamics'. This link has been done using the web site of both commissions and through the sharing of information, easy to do for this term as the presidents of both commissions are the same person (V. Dehant).

(c) Encouraging and stimulating the services related to Commission 19. This has again been performed by using money of Descartes Prize as several proposals have the objectives to help the IERS Product Center on Global Geophysical Fluids.

(d) One important concern related to our commission is the impact of the 2005 tsunami on Earth rotation. In addition to this, following the adoption of new resolutions on the definition of the way to pass from the terrestrial reference frame to the celestial reference frame, using the Non Rotating Origin (NRO), the Royal Observatory of Belgium has decided to dedicate some money to perform 3D representations which explain it. These $3 \mathrm{D}$ representations are on the web. Still some explanations must be added. The new link between the frames takes full advantage of precision available with modern VLBI and other space techniques. The new precession-nutation models are an important element of high precision Earth rotation.

The web pages of Commission 19 are: http://www.astro.oma.be/IAU/

\section{Report of the International Earth Rotation and Reference Frame Service}

Bernd Richter and Wolfgang R. Dick; Chopo Ma

\subsection{General activities}

In 2003 the IERS was renamed the International Earth Rotation and Reference Systems Service (IERS) or in French, Service international de la rotation de la Terre et des systèmes de reference. The new name better reflects the fact that the activities of the IERS do not only consist in producing Earth orientation parameters but also in defining and maintaining the celestial and terrestrial reference systems and frames. Details about all IERS activities may be found in the Annual Reports and at the IERS web sites.

\subsubsection{Publications and web sites}

The following IERS Technical Notes were published between 2002 and 2005:

- No. 29: N. Capitaine et al. (eds.): Proceedings of the IERS Workshop on the Implementation of the New IAU Resolutions, 2002. 
- No. 30: B. Richter et al. (eds.): Proceedings of the IERS Workshop on Combination Research and Global Geophysical Fluids, 2003.

- No. 31: C. Boucher, Z. Altamimi, P. Sillard, and M. Feissel-Vernier: The ITRF2000, 2004.

- No. 32: D.D. McCarthy and G. Petit (eds.): IERS Conventions (2003), 2004.

- No. 33: B. Richter et al. (eds.): Proceedings of the IERS Workshop on site colocation, 2005.

The IERS Annual Reports give information about activities of all IERS components, as well as on IERS structure, Terms of Reference and contact addresses. For rapid information, the Central Bureau issues IERS Messages which are being sent to about 2000 users. Earth orientation data are distributed in IERS Bulletins A, B, C, and D (see below). The IERS components run about 20 web sites to present general information, data and publications. The central web site www.iers.org maintained by the Central Bureau provides information about IERS in general, its components and Earth rotation and reference systems as well as links to other servers. The web site contain also online versions of all publications.

\subsubsection{Meetings}

The IERS Workshop on Combination Research and Global Geophysical Fluids was organized at Munich, Germany, 18-21 November 2002. The first part of the workshop covered the different aspects of the comparison and combination of the results of all major space geodetic techniques. The second part focused on the Global Geophysical Fluid Centre, the present status of its products as well as its role in future. The IERS Retreat 2003 was held at Paris, France, March 31-April 1, 2003. The outcome was the following: new naming of IERS; decisions about contributions to IGGOS; closer cooperation with the gravity field and the altimetry communities; steps towards a better interaction between the Global Geophysical Fluid Centre and the other IERS components; start of the Combination Pilot Project. The IERS Workshop on site co-location held at Matera, Italy, 23-24 October 2003, gave important recommendations concerning local ties and local survey measurements. The Workshop on the IERS Combination Pilot Project, organized at Napa, CA, USA, 11 December 2004, discussed the first results of this project.

\subsection{Activities of the IERS components}

\subsubsection{Central components}

The IERS Directing Board met once or twice yearly. Summaries of the meetings are available in the IERS Annual Reports. The Central Bureau coordinated the work of the Directing Board and the IERS in general, organized meetings and issued publications. It maintains the IERS Data and Information System based on modern technologies for internet-based exchange of data and information. The system provides general information on the structure and the components of the IERS and gives access to all products. The work of the Analysis Coordinator focused on initiating and coordinating the Analysis Campaign to align EOPs to ITRF2000 / ICRF, the SINEX Combination Campaign, and the Combination Pilot Project.

\subsubsection{Technique Centres}

The Technique Centres are autonomous independent services, which cooperate with the IERS. The International GNSS Service (IGS), formerly the International GPS Service, is committed to provide the highest quality data and products as the standard for global navigation satellite systems (GNSS). Current GPS and GLONASS products 
support scientific objectives including realization of the ITRF, monitoring Earth rotation, and many others. Pilot Projects have been launched to develop new products and services. The International Laser Ranging Service (ILRS) is responsible for the coordination of SLR/LLR missions, technique development, operations, analysis and scientific interpretation. Since mid-2003, it has been producing weekly time-series of solutions for station coordinates and Earth orientation parameters. For a report of the International VLBI Service (IVS) see Section 4 below. The International DORIS Service (IDS) was created by the International Association of Geodesy in July 2003 as the result of a successful DORIS Pilot experiment. The main contribution of IDS to Earth rotation studies is the production of series of daily pole coordinates and weekly Terrestrial Reference Frames. The quality of these results has improved with time.

\subsubsection{Product Centres}

The Earth Orientation Centre is responsible for monitoring of long-term earth orientation parameters, publications for time dissemination and leap second announcements. It issues IERS Bulletins B, C, and D. For a detailed report see Section 9.16 (SYRTE Department of Paris Observatory) below. The Rapid Service/Prediction Centre is responsible for providing Earth orientation parameters on a rapid turnaround basis. It issues IERS Bulletin A. For a detailed report see Section 9.14 (US Naval Observatory) below. The Convention Centre released the electronic edition of the IERS Conventions (2003) in November 2003, and the corresponding paper edition was published in 2004. A new web site includes a discussion forum and pages for the Conventions updates. The ICRS Centre has been working on validation of individual reference frames by comparison with ICRFExt.1, on monitoring source structure to assess astrometric quality, on the maintenance of the Hipparcos link, on linking the ICRF to frames at various wavelengths, and on other studies. The ITRS Centre participated in complete surveys of some co-location sites, contributed to specifications for ITRF densification, developed the tools and methodology for generating the ITRF from SINEX inputs from the various space geodesy techniques, and maintained the IERS network. A new ITRS Web site was developed. The Global Geophysical Fluids Centre (GGFC) consists of eight Special Bureaus (SB) for Atmosphere, Core, Gravity/Geocentre, Hydrology, Loading, Mantle, Oceans, and Tides. These provide data related to global geophysical fluids such as co-seismic excitation of Earth rotational and gravitational changes, glacial isostatic adjustment, core angular momentum changes, geocentre variations, oceanic tidal angular momentum, oceanic tidal variations in earth rotation, low-degree spherical harmonics of ocean and atmospheric tides, models for global oceanic angular momentum, models for oceanic centre-of-mass, a model for ocean bottom pressure, measurements of ocean bottom pressure, continental water storage and water flux, effective atmospheric angular momentum functions, spherical harmonic coefficients of surface pressure, global friction torque and global mountain torque, and Earth surface deformation due to surface mass loading. During the last three years, the amount of data and their quality have significantly improved in several cases.

\subsubsection{Combination Centres and Working Groups}

Eleven Combination Research Centres worked on the development of methods and software for the combination of data and products from different techniques. Three ITRS Combination Centers are responsible to provide ITRF products by combining ITRF inputs. Several of these Combination Centres take part in the Combination Pilot Project. At the beginning of 2004, the IERS Directing Board established two Working Groups. The Working Group on Site Survey and Co-location coordinates a Site Survey and Co-location Pilot Project with the intention of developing future recommended IERS standards for 
site survey and co-location. The major task of the Working Group on Combination is the coordination of the IERS Combination Pilot Project.

\section{Report of the International VLBI Service for Geodesy and Astrometry}

Analysis Coordinator: Axel Nothnagel

The International VLBI Service for Geodesy and Astrometry (IVS) has continued to fulfill its role as a service within the IAU by providing necessary products for the densification and maintenance of the celestial reference frame as well as for the monitoring of earth orientation parameters (EOP). In early 2002, IVS changed from the institutiondriven observing programs and related products to its own programs and products. Since then, weekly network observing sessions on Mondays and Thursdays are carried out routinely for rapid turnaround measurements of the complete set of EOP including nutation offsets. Data bases and results are available no later than 15 days after each session. On average, a total of more than 1000 station days per year were used in about 180 geodetic sessions during the year increasing the average days per week which are covered by VLBI network sessions to 3.5. Daily 1-hour UT1 Intensive measurements are continued to be made on almost all weekdays (Monday through Friday) on the baseline Wettzell (Germany) to Kokee Park (Hawaii, USA). During 2004, Saturday and Sunday sessions were added on the baseline Wettzell (Germany) to Tsukuba (Japan), making UT1 measurements now available every day. Here, the VLBI data is transferred electronically to the correlator at Tsukuba reducing the time between observations and dissemination of results considerably. Dedicated sessions for densification and maintenance of the celestial reference frame (CRF), coordinated by the U.S. Naval Observatory, also provide astrometric observations of "new" sources. The Very Long Baseline Array (VLBA), operated by the National Radio Astronomy Observatory (NRAO), continued to allocate six observing days for astrometry and geodesy. These sessions included the 10 VLBA stations plus up to 10 geodetic stations, providing state-of-the-art astrometry as well as information for mapping ICRF sources.

\section{SOFA (Standards of Fundamental Astronomy)}

President: Patrick Wallace

The international SOFA Review Board provides an authoritative set of fundamentalastronomy algorithms through a web site hosted at the Rutherford Appleton Laboratory in the UK (www.iau-sofa.rl.ac.uk). SOFA's second issue of software was made in April 2003; it contained 121 Fortran routines including, in particular, definitive implementations of the IAU 2000 precession-nutation models and related quantities. Since then, Board members have been participating in the efforts of IAU Division I Working Groups to establish revised nomenclature and to select an improved precession model. A third issue of the SOFA software occurred in September 2005, comprising minor improvements to existing routines plus provision for the UTC leap second at the end of 2005.

\section{Report from the individual institutions}

\subsection{Royal Observatory of Belgium}

ROB has worked on test on the validity of the atmospheric torque approach to compute the effect of the atmosphere on polar motion, nutation, and length-of-day variations 
(de Viron O. and Dehant V., 2003, de Viron et al., 2005). ROB has also been working on the remaining error sources in the nutation at the sub-milliarcsecond level (Dehant et al., 2003a) and on the electromagnetic torque at the core-mantle boundary (Huang C. et al., 2003).

On the other hand, ROB has been interested in the planet Mars and in particular in its polar motion and its nutation for a future experiment involving radioscience. Theoretical developments as well as simulations have been performed. The tides of terrestrial planets have also been investigated. Both orientation parameters and tides are related to interior modeling of the planets which has been addressed intensively at ROB (Van Hoolst et al., 2003, Yseboodt et al., 2003, Dehant et al., 2003b, Defraigne et al., 2003, Duron et al., 2003, Rosenblatt et al., 2004, Dehant et al., 2004, Verhoeven et al., 2005, Karatekin et al., 2005, Dehant et al., 2005).

\subsection{Astronomical Institute, Academy of Sciences of the Czech Republic and Faculty of Civil Engineering, Czech Technical University, Prague}

New combined astrometric catalogue EOC-2 (Earth Orientation Catalogue) has been provided by combination of astrometric observations of latitude/universal time with new astrometric catalogues (ARIHIP, TYCHO-2) (Vondrak and Ron, 2005a). The improvement of the accuracy of proper motions over Hipparcos catalogue is remarkable and the new catalogue appeared as an improved optical reference frame for long-term Earth rotation studies. Two new solutions of Earth Orientation Parameters (EOP) from optical astrometry observations in the interval 1899.7-1992 based on the EOC-2 catalogue were made in 2004. Using the polar motion from the solution called OA04 (Vondrak and Ron, 2005b) a possible mechanism was shown that could be responsible for the great change of Chandler wobble phase in 1923-1940. The celestial pole offsets from the solution called OA04a (Ron et al., 2005) were used for possible validation of the P03 precession model.Two combinations of the VLBI and GPS observations of celestial pole offsets by the "method of combined smoothing" (Vondrak and Cepek, 2000) were made. First was used to test the new IAU precession-nutation model (Vondrak et al., 2003). The free core nutation was analyzed on base of the next combination of VLBI/GPS celestial pole offsets (Vondrak et al., 2005). The method for a non-regular combination of results of different techniques, based on combining the station position vectors transformed into the celestial reference frame Kostelecky and Pesek, 2003), was applied to the data of the IERS SINEX Combination campaign (Pesek and Kostelecky, 2005) and of the IERS Combination Pilot Project. After introducing rates of the transformation parameters, the results became more stable. The method thus allows short-term combinations to retain short periodic effects as well as the long-term solutions (Kostelecky and Pesek, 2006).

\subsection{GeoForschungsZentrum Potsdam}

Wünsch (2002) balances the contributions of atmosphere, ocean and hydrology to the annual and semi-annual polar motion using models then available.

Greiner-Mai et al. (2003) review the core contributions to polar motion and gravity variations. They discuss coupling torques and the relative angular momentum of the core.

Hengst (2003) applies wavelet analysis to time series of OAM (oceanic angular momentum) from the ocean circulation model OMCT (M. Thomas, Dresden).

Guo et al. (2005a) re-discuss the double-peak spectrum of the Chandler wobble. Guo et al. (2005b) attempt to detect the inner core wobble (ICW) by comparing the spectrum of polar motion data with that of (AAM + OAM).

Haas and Wünsch (2005) use the CONT02 VLBI data to search for terdiurnal and other terms in the residual time series (observations minus IERS model). 
6.4. Institute of Applied Astronomy of the Russian Academy of Sciences (IAA)

There were the following activities during last three years:

(a) IAA supports EOP Service including everyday processing of the VLBI, SLR and GPS observations. Also long-term time series of EOP, station coordinates and tropospheric parameters are regularly computed. During last three years significant improvement of software and hardware was performed. Results are submitted to IERS and IVS, a new radio source catalogue (Malkin et al., 2005).

(b) Investigation of the systematic differences of EOP and TRF series, and source catalogues; investigation of combination strategy (Malkin, 2002; Panafidina, 2002; Malkin, 2003a; Sokolova, 2005).

(c) Investigation of the FCN contribution to nutation started, and planned to continue (Malkin and Terentev, 2003a; Malkin and Terentev, 2003b; Malkin, 2004a; Malkin, 2004b; Shirai et al., 2005).

(d) Investigation of European GPS stations movement. A new combined EPN solution was computed. Comparison of baseline length variations obtained with VLBI and GPS techniques is underway (Panafidina, 2002; Panafidina and Malkin, 2004; Panafidina et al., 2004).

(e) New program package QUASAR for processing of the VLBI observations has been developed, the first global $\mathrm{EOP}+\mathrm{TRF}+\mathrm{CRF}$ solutions are under investigation (Gubanov et al., 2002; Gubanov, 2004; Gubanov et al., 2004).

(f) A theory of the deformable Earth with the two-layer fluid core is constructed by numerical integration. Fitting to VLBI series shows the rms difference of nutation angles at the level of 0.1 mas for 1995-2005 (Krasinsky, 2003; Krasinsky, 2005; Krasinsky and Vasilyev, 2005).

Results and other related info can be found at http://www.ipa.nw.ru/PAGE/DEPFUND/ GEO/

\subsection{Hydrometcenter of Russia, Moscow}

New results on the fortnight's and week's duration oscillations of the equatorial components of the atmospheric angular momentum were obtained. The zonal tides transformation mechanisms in the atmosphere were studied. It is shown that the atmospheric contribution to the nutation essentially varies in time (Sidorenkov, 2003a).

The Influence of the atmospheric and oceanic circulation on the plate tectonics was studied. It is shown that under the effect of the atmospheric and oceanic forces displacement of the plates is possible (Sidorenkov, 2003b).

The time series of the mass of water in the World Ocean and ice in Antarctica and Greenland for 1891-2004 was calculated using the Earth's rotation parameters. The computed (theoretical) series have a close correlation with the empirical series for Antarctica and Greenland (Sidorenkov, 2003c, 2004).

\subsection{Space Research Center of the Polish Academy of Sciences}

Subdiurnal nutations (A. Brzezinski). This description concerns the lunisolar perturbations in Earth rotation associated with the multipole structure of the mass distribution within the Earth. This effect is of the order of 0.1 milliarcseconds therefore it has been neglected in earlier investigations. The discussion of the IAU Commission $19 \mathrm{WG}$ on $\mathrm{Nu}-$ tation, coordinated by A. Brzezinski, led to an agreement on the model whose accuracy is expected to be at the level of 1 microarcsecond (Brzezinski and Mathews, 2003). The model was included in the IERS Conventions 2003 as an element of the transformation between the terrestrial and celestial reference systems (IERS conventions 2003, Table 5.1 and the Fortran program PMsdnut.for). 
Oceanic excitation of Earth rotation (A. Brzezinski). This research concerns the excitation of Earth rotation by the coupled atmosphere/ocean system (Brzezinski, 2003; Brzezinski et al., 2005). An important new result is an estimation of the non-tidal oceanic excitation of nutation and diurnal/semidiurnal polar motion based on the output from the barotropic ocean model (Brzezinski et al., 2004).

Prediction of Earth Orientation Parameters (W. Kosek). Different stochastic prediction methods were applied to predict pole coordinates in the polar coordinate systems (Kosek 2003, Kosek et al. 2004, Kalarus and Kosek 2004, Kosek et al. 2004). Least-squares extrapolation based on the sinusoidal model of FCN and the autoregressive approach were applied for prediction of the observed irregular component of nutation (Brzezinski and Kosek 2004). Different stochastic prediction techniques were also applied to predict pole coordinates and UT1-UTC data and the most accurate predictions were obtained using the combination of the least-squares extrapolation and the autoregressive forecast (Kosek et al. 2004, 2005, Kosek et al. 2005).

Free oscillations in Earth rotation. This research concerned theoretical modeling, prediction and the excitation processes for CW and FCN (Brzezinski, 2005a,b; Brzezinski and Kosek, 2004, Kosek and Kalarus 2003, Kosek 2004, 2005). The exchange of the atmospheric angular momentum and ocean angular momentum with each other and with the solid Earth at the frequency one cycle per year is not only the cause of the excitation of the annual oscillation in polar motion but also the Chandler one.

Studies of the impact of different global and regional geophysical fluids (atmosphere, ocean, hydrosphere) on polar motion excitations were carried out. (1) Regional atmospheric excitation functions were computed first time in 3312 equal-area sectors and the spatial variability of the atmospheric and oceanic excitations of polar motion was examined (Nastula, Salstein, Ponte, 2003). (2) Comparisons of correlations and covariances between the regional atmospheric pressure excitation function of polar motion and global geodetic excitation function of polar motion computed in two spectral bands annual and semi-annual ones and in two sets of sectors of different sizes are presented (Nastula and Kolaczek, 2005). (3) Atmospheric excitation functions of polar motion computed from 19 models of the Atmospheric Model Intercomparison Project (AMIP) were analyzed and compare with geodetic excitation function in the period of 17 years (Nastula, Salstein, Kolaczek, 2005). (4) The impact of the El Nino phenomena on correlations between seasonal oscillations of atmospheric and geodetic excitations of polar motion was demonstrated (Kolaczek, Nastula, Salstein, 2003). (5) The polar motion excitation by geophysical fluids was investigated by adding various oceanic series to atmospheric ones in the wide spectral band from seasonal to short period oscillations (Nastula, Salstein, Kolaczek, 2003; Brzezinki et al, 2005; Nastula, 2005,). (6) The impact of the addition of the ocean to the atmospheric excitation of polar motion on the variability in the spectra of geophysical excitation functions of polar motion and in the correlation between geophysical and geodetic excitation functions was investigated (Nastula, Salstein, Kolaczek, 2003, Kolaczek and Nastula, 2004, Nastula, 2005). The analyses show that quality of the oceanic excitation series depends on the considered frequency band and the analyzed time period, although adding the oceanic excitation brings the modeled geophysical excitation closer to observed geodetic excitation (Nastula 2005, Brzezinski et al., 2005). (7) It was shown that the correlation between combined oceanic and atmospheric and geodetic polar motion excitation functions is significant at periods between 4 and 10 days (Nastula and Gambis, 2004). (8) Analysis of hydrological excitation of polar motion was carried out on the base of the model of the Hydrological Angular Momentum (HAM) available from the GGFC of the IERS. This hydrological excitation function does not improve the agreement between and geophysical excitation functions in the considered 
period of time and in some periods of time diminishes this agreement. Others models of HAM are studied too (Nastula and Kolaczek, 2005) (9) Spectral analysis of high resolution VLBI and GPS results of polar motion determinations available over the restricted period of the CONT02 campaign allows detecting oscillations of these polar motion data with 8 hours and weak oscillations with 6 hours (Schuh et al. 2004).

\subsection{Institute of Astronomy and Geodesy of Complutense University of Madrid, Spain}

The main scientific contributions during the last triennium are the following:

A common research work with the department of SYRTE at Paris Observatory concerning to the study of the modeling of the free rotation of any celestial body, both by the intermediary of numerical integration and by the intermediary of analytical calculations have been undertaken (Souchay et al., 2003), (Folgueira and Souchay, 2005).

M. Folgueira also participates in a Descartes sub-project entitled: "Advances in the integration of the equations of the Earth's rotation in the framework of the new parameters adopted by the IAU 2000 Resolutions". The first part of this project is carried out in the department of SYRTE at Paris Observatory (supervised by N. Capitaine and J. Souchay). The topic is the integration of the equations of the Earth rotation explicitly expressed in terms of the celestial rectangular coordinates of the CIP unit vector. The second part (supervised by V. Dehant) is carried out at Royal Observatory of Belgium and it is devoted to the study of the geophysical effects of considering the new solutions for the Earth's rotation in the framework of the new parameters adopted by the IAU 2000 Resolutions.

\subsection{Jet Propulsion Laboratory (JPL), USA}

During the past triennium, JPL continued to investigate the causes of observed variations in the Earth's orientation, focusing on the influence of the atmosphere and oceans. Dickey et al. (2003) continued their investigation of poleward propagating atmospheric zonal wind anomalies and Marcus et al. (2004) investigated differences between the angular momentum and torque approaches that are used to compute the effect of the atmosphere on the nutations. In a series of papers, the effects of the atmosphere and oceans on polar motion (Gross, 2004; Gross et al., 2003) and length-of-day (Gross, 2004; Gross et al., 2004a) on subdecadal and decadal (Gross et al., 2005) time scales were investigated. Gross (2005a) also reviewed the influence of the oceans on polar motion. The period and Q of the Chandler wobble was estimated by Gross (2005b) using atmospheric and oceanic angular momentum estimates to model the excitation of the Chandler wobble. The contribution of laser ranging measurements to Earth orientation determination was discussed by Gross (2003a) and the impact of different hot spot reference frames on the drift in the pole path was evaluated by Argus and Gross (2004). The consistency of Earth rotation and degree-2 gravitational field changes was discussed by Gross (2003b), with Gross et al. (2004b) examining the consistency of Earth rotation and degree-2 changes in the shape of the Earth.

JPL also continued to support tracking and navigation of interplanetary spacecraft by using a Kalman filter to combine and predict Earth orientation parameters. The EOP measurements used in the combination are taken by both in-house and extramural measurement programs. Reference series of Earth orientation parameters, the latest being SPACE2004, COMB2004, and POLE2004, continue to be produced annually and, along with reports describing their generation, can be obtained by anonymous ftp to iftp://euler.jpl.nasa.gov/keof/combinations;. The near-real-time Earth orientation requirements of the interplanetary spacecraft navigation teams are met by twice-per-week updating the annually generated EOP reference series and then predicting the future 
evolution of the EOPs. The updated and predicted EOP series can be obtained by anonymous ftp to iftp://euler.jpl.nasa.gov/keof/predictions;. Chin et al. (2004) discussed the prediction of polar motion using models and forecasts of the polar motion excitation functions, and Chin et al. (2005) evaluated the uncertainty in measurements of the Earth orientation parameters.

Lunar laser ranging data are also analyzed at JPL for Earth rotation. First the data are fit from 1970 to the present with a global solution with various physical model parameters including station locations and rates. Then the residuals from the global fit are processed to extract UT0 and variation of latitude for individual stations and individual days. The consistent set of values runs from 1970 to the present.

\subsection{The US Naval Observatory (USNO), USA}

The U.S. Naval Observatory (USNO) continued serving as the IERS Rapid Service/Prediction Centre. The Centre produces the IERS Bulletin A on a rapid turnaround basis, primarily for real-time users and others needing the highest quality Earth orientation parameter (EOP) information before the IERS final values are available. The emphasis of the Centre is on near-term prediction (weeks) rather than long-term prediction (years) of EOP. Current procedures and results are given in the annual report of the IERS. Our ability to function as the Rapid Service/Prediction Centre is enhanced by our active involvement with the Technique Centers. As an Associate Analysis Center of the International GNSS Service, USNO has the opportunity to examine ways to improve the contribution of GPS observations to EOP. As an Operations Center, Correlator, and supporter of observing stations within the International VLBI Service, USNO is intimately involved in all aspects of the collection of VLBI observations and understanding their impact on EOP. Within the last three years, significant improvements have included the enhanced GPS UT1-like quantity that improves UT1-UTC combination results at solution epoch, the introduction of AAM UT1-like quantity that improves UT1-UTC prediction, the automation of data retrieval and updating that reduces processing time, and the compliance with IAU 2000 resolutions with respect to the production of new nutation series, dX and dY (Wooden et al., 2004, Wooden et al., 2005, Johnson et al., 2005a). Additionally, two internal studies have assessed the R1 and R4 VLBI experiments with respect to the operational aspects of producing daily EOP combinations.

A lot of work has been dedicated to improvement on IERS Rapid Service/Prediction Centre products and the performance of Bulletin A, which includes the development of new strategies.

In addition to being the Rapid Service/Prediction Centre, USNO continued its collaborative research into many aspects of Earth rotation from the mechanisms of Earth rotation excitation to the role of ground water on the Earth's shape (Johnson and Price, 2003), to the differences in angular momentum from different atmospheric and oceanic models (Johnson, 2004), to the Sumatra Earthquake (Johnson et al., 2005b, 2005c), to the temporal variations of the Earth's gravitational field using surface pressure fields (Johnson et al., 2005d), and to various aspects of nutation (Lambert and Capitaine, 2004, Lambert, 2004, McCarthy, 2005).

\subsection{NASA Goddard Space Flight Center: VLBI Group}

The Goddard VLBI group continued to support the direction, coordination and oversight of the IVS observing programs and stations that provide regular EOP measurements for scientific studies and time keeping, particularly nutation and UT1. The group was the IVS Operation Center responsible for one of the weekly rapid EOP observing programs as well as the bi-monthly 20-station network using the VLBA and geodetic stations 
for TRF connection and astrometry. The group continued as one of the IVS analysis centers contributing to the IVS combined EOP and daily UT1 products and to the IVS input to ITRF2004. An IVS astrometric monitoring program was begun by the group in 2004 to improve the data set of stable and potentially stable sources for the next radio ICRF. Research continued on modeling geophysical signals seen in VLBI data, such as atmosphere loading (Petrov and Boy, 2004) and ocean loading (Petrov and Ma, 2003).

\subsection{SYRTE Department of Paris Observatory}

Reference systems for Earth rotation. A set of stable compact radio sources has been proposed, based on the analysis of VLBI-derived time series of right ascensions and declinations (Feissel-Vernier 2003) that has been used for improving the quality of the realization of the ICRF (Arias and Bouquillon 2004). The team has participated in the preparation of the ICRF-Extension 2 (Fey et al. 2004). The consideration of time stability of extragalactic radio sources observed by VLBI has been shown to allow the realization of more consistent celestial reference frames appropriate for the determination of precession and nutation corrections (Feissel-Vernier et al. 2005).

Astrometric modeling of Earth rotation. There has been an active participation to IAU Division 1 Working Groups on "Precession and the Ecliptic" chaired by J. Hilton and on "Nomenclature for fundamental astronomy" chaired by N. Capitaine. IAU 2000 expressions have been provided for the position of the CIP and the CIO in the GCRS (Capitaine et al. 2003a) and for implementing the new IAU definition of UT1 (Capitaine et al. 2003b). A new model of precession has been developed (Capitaine et al. 2003c) that has been compared with various models and observations (Capitaine et al 2004, Ron et al. 2005). This model, denoted P03, is intended to replace the precession part of the IAU 2000 precession-nutation (Capitaine et al 2005). The dynamical equations of the rotation of a rigid Earth have been established in terms of the Earth Orientation Parameters (EOP) of the new paradigm that is recommended by the IAU 2000 resolutions (Capitaine et al. 2005, Folgueira et al. 2005).

Geophysical modeling of the Earth rotation. Coupling effects between Earth rotation and nutation have been re-evaluated by Lambert (2003, 2004) and Lambert and Capitaine (2004) including second order terms. The J2 variations observed by space geodetic have been used by Bourda and Capitaine (2004) for improving the precession-nutation expressions. Further studies have been performed on the effect of the atmosphere, solar activity and earthquakes on polar motion, lod and nutation (e.g. Gambis and Sillard 2004, Varga et al. 2005). The temporal variations of the Earth gravity field as derived from geodetic data have been used by Bourda $(2004,2005)$ to contribute to the understanding of the variations in EOP. Free motion of elastic bodies with respect to an inertial and body-fixed frame have been studied by Souchay and Fogueira (2003) with application to the Earth and the effects of the triaxiality on the rotation of celestial bodies have been studied by Souchay et al. (2004) with application to the Earth, Mars and Eros. Hamiltonian formalism has been used to model the free polar motion of a triaxial and elastic body, especially for the Earth (Folgueira and Soucahy 2005).

Multi-technique computation of the Earth orientation parameters. So far, combinations of Earth Orientation Parameters (EOP) series and the terrestrial reference frame (TRF) are performed independently. This prevents to get an optimal consistency. A new approach based on a combination of both EOP and TRF at the observation level is being developed. The processing of the various data derived from the space techniques SLR, LLR, GPS, DORIS and VLBI are done using a single software package (GINS/Dynamo) to provide a consistent set of Earth rotation parameters and station network coordinates on a weekly basis. This project is performed in the framework of the "Groupe de 
Recherches de Géodesie Spatiale" (GRGS). The final analysis of weighting and combining individual products is done at the Paris Observatory (Biancale et al. 2002, Coulot et al. 2004, Gambis et al. 2005).

Operational and scientific activities within to international services. We are deeply involved in different international service, the IERS (Gambis, 2004, Bizouard 2004, Gambis 2005, Altamimi et al. 2005), the IVS (Gontier, 2004) and the ILRS (Chapront and Francou, 2004).

Journées Systèmes de référence spatio-temporels. These Journées, with several sessions devoted to Earth rotation, have been organized in 2003 by A. Finkelstein and N. Capitaine at the Institute of Applied Astronomy of the Russian Academy of Sciences, St. Petersburg, Russia, in 2004 by N. Capitaine at Paris Observatory, in 2005 by B. Kolaczek, A. Brzezinski and N. Capitaine at the Space Research Center of the Polish Academy of Sciences.

\subsection{Shanghai Observatory (SHAO)}

Efforts are still going on in the past three years since Prof. Li first took the charge of solving the problem demanded by the IAU Comm. 19 and IAG in 1991: "variations in the deflection of the vertical..." ("Application of optical astrometry time and latitude program", Resolution of the Commission 19 of the IAU in 1991). The relationship between the earthquakes and the geoid deformation at Beijing not only provide us evidence in which the existence of the Plumb Line Variations (PLV) at Beijing becomes more conclusive, but also disclose a new usage of the optical astrometric observations in the studies related to Earth Sciences.

In recent years, C.L. Huang and SHAO group are working with ROB colleagues on the theoretical study of the non-rigid Earth nutation and its coupling with geomagnetic field. They got explicit scalar equations of infinitesimal elastic-gravitational motions in the rotating, slightly elliptical fluid outer core of the Earth, and derived the coupling equations between the nutation and the geomagnetic field in generalized spherical harmonics expansion. These studies are still going on.

\section{References}

Altamimi, Z., Boucher, C., and Gambis, D., 2005, "Long-term stability of the terrestrial reference frame.", Advances in Space Research, 36, 3, 342-349.

Altamimi, Z., Sillard, P., and Boucher, C., 2005, "The impact of a No-Net-Rotation Condition on ITRF2000.", Geophysical Research Letters, 30, 2, 36-1, CiteID 2002, DOI 10.1029/2002GL016279.

Argus, D.F., and Gross, R.S., 2004, "An estimate of motion between the spin axis and the hotspots over the past century.", Geophys. Res. Lett., 31(6), L06614, DOI: 10.1029/2004GL019657.

Arias, F., and Bouquillon, S., 2004, "Representation of the International Celestial Reference Frame (ICRF) by different sets of selected radio sources.", Astron. Astrophys., 422, 11051108.

Bizouard, C., 2004, "Interactive Earth rotation Parameters through the web.", in: Proc. Journées Systèmes de Référence Spatio-Temporels 2003, eds. A. Finkelstein and N. Capitaine, 156159.

Bouquillon, S., Kinoshita, H., and Souchay, J., 2003, "Extension of Cassinis laws.", Celest. Mechanics, 86, 29-57.

Bourda, G., and Capitaine, N., 2004, "Precession, nutation and space geodetic determination of the Earths gravity field.", Astron. Astrophys., 428, 691-702

Bourda, G., and Capitaine, N., 2004, "Temporal variations of the gravity field and Earth precession-Nutation.", Proc. Journées Systèmes de Référence Spatio-Temporels 2003, ed. A. Finkelstein and N. Capitaine, 203-204. 
Bourda, G., 2004, "Earth Orientation and Temporal Variations of the gravity field.", Proc. SF2A 2004, eds. F. Combes et al., EDP Sciences 2004, 3-6.

Bourda, G., 2005, "Earth Rotation and Variations of the gravity field, in the framework of the Descartes-Nutation" Project.", Proc. Journées Systèmes de Référence Spatio-Temporels 2004, ed. N. Capitaine, 132-133.

Brzezinski, A., and Mathews, P.M., 2003, "Recent advances in modeling the lunisolar perturbation in polar motion corresponding to high frequency nutation: report on the discussion of the IAU Comm. 19 WG on Nutation.", Proc. Journées Systèmes de Référence SpatioTemporels 2002, eds. N. Capitaine and M. Stavinschi, Ars Docendi, Paris, 101-108.

Brzezinski, A., 2003, "Oceanic excitation of polar motion and nutation an overview.", Proc. IERS Workshop on Combination Research and Global Geophysical Fluids, eds. B. Richter, W. Schwegmann and W. R. Dick, IERS Technical Note No. 30, Verlag des Bundesamts fuer Kartographie und Geodaesie, Frankfurt am Main, 144-149.

Brzezinski, A., and Kosek, W., 2004, "Free core nutation: stochastic modeling versus predictability.", Proc. Journées Systèmes de Référence Spatio-Temporels 2003, eds. A. Finkelstein and N. Capitaine, Inst. of Applied Astronomy of the Russian Acad. of Sciences, St. Petersburg, 99-106.

Brzezinski, A., Ponte, R.M., and Ali, A.H., 2004, "Non-tidal oceanic excitation of nutation and diurnal/semidiurnal polar motion revisited.", Journal of Geophysical Research Solid Earth, 109, B11, DOI: 10.1029/2004JB003054.

Brzezinski, A., 2005a, "Review of the Chandler Wobble and its excitation.", Proc. of the Workshop Forcing of polar motion in the Chandler frequency band: a contribution to understanding inter-annual climate variations, eds. H.-P. Plag, B. Chao, R. Gross and T. van Dam, European Center for Geodynamics and Seismology, Luxembourg City, 109-120.

Brzezinski, A., 2005b, "Chandler wobble and free core nutation: observation, modeling and geophysical interpretation.", Artificial Satellites, 40, 1, 21-33.

Brzezinski, A., Nastula, J., Kolaczek, B., and Ponte, R.M., 2005, "Oceanic excitation of polar motion from intra-seasonal to decadal periods.", in 'A window on the future of geodesy', ed. F. Sanso, IAG Symposia Vol. 128, Springer Verlag, Berlin Heidelberg, 591-596.

Brzezinski, A., Nastula, J., Kolaczek, B., and Ponte, R.M., 2005, "Oceanic excitation of polar motion from intra-seasonal to decadal periods.", in: Proceedings of the International Association of Geodesy, A window on the future of Geodesy, Sapporo Japan, June 30-July 11, 2003, Springer-Verlag Berlin Heidelberg 2005, F. Sanso (eds.), 501-596.

Capitaine, N., Chapront, J., Lambert, S., and Wallace, P., 2003a, "Expressions for the Celestial Intermediate Pole and Celestial Ephemeris Origin consistent with the IAU 2000A precession-nutation model.", Astron. Astrophys., 400, 1145-1154.

Capitaine, N., Wallace, P., and McCarthy, D.D., 2003b, "Expressions to implement the IAU 2000 definition of UT1.", Astron. Astrophys., 406, 1135-1149.

Capitaine, N., Wallace, P., and Chapront, J., 2003c, "Expressions for IAU 2000 precession quantities.", Astron. Astrophys., 412, 567-586.

Capitaine, N., Wallace, P., and Chapront, J., 2004, "Comparison between high precision precession models for the ecliptic and the equator.", Astron. Astrophys., , 421, 365-379.

Capitaine, N., 2004, "Highlights of the scientific meetings of Division I" and : Microarcsecond models for the celestial motions of the CIP and the CEO, Journées Systèmes de Référence Spatio-Temporels 2003, A. Finkelstein and N. Capitaine (eds), 339-342.

Capitaine, N., 2004, "Recent developments in the concepts and models for fundamental astronomy", La Semaine de 1Astrophysique Franaise, Paris, juin 2004, in: Scientific highlights 2004, F. Combes et al. (eds), EDP Sciences, 7-11.

Capitaine, N., and McCarthy, D.D., 2004a, "The IAU 2000 Recommendations on Reference Systems and their Application.", American Astronomical Society Meeting, June 2004, AAS204.2801C.

Capitaine, N., and Wallace, P., 2004b, "Improvements in the precession-nutation models.", Proc. Journées Systèmes de Référence Spatio-Temporels 2004, ed. N. Capitaine, 49-54

Capitaine, N., and Wallace, P., 2004c, "The VLBI Contribution to Precession (Present and Future).", International VLBI Service for Geodesy and Astrometry 2004 General Meeting Proceedings, ed. by N.R. Vandenberg and K.D. Baver, NASA/CP-2004-212255, 2004. 
Capitaine, N., Hohenkerk, C., Andrei, A., Calabretta, M., et al. 2004a, "Report of the IAU Division 1 Working Group on Nomenclature for Fundamental astronomy (NFA).", Proc. Journées Systèmes de Référence Spatio-Temporels 2004, ed. N. Capitaine, 161-165.

Capitaine, N., Wallace, P., and Chapront, J., 2004b, "Improvement of the IAU 2000 precession model.", Astron. Astrophys., 432, 355-367

Capitaine, N., 2005, "Reference Systems: recent developments.", in Artificial satellites: Journal of planetary Geodesy, 40, 1, 7-20

Capitaine, N., 2005, "Oppolzer terms: a review.", FGS Workshop on"Ring Laser Gyroscopes and Earth Rotation.", Wettzell, March 24-25, 2004.

Capitaine, N., Wallace, P., and Chapront, J., 2005, "Improvement of the IAU 2000 precession model.", Astron. Astrophys., 432, 1, 355-367.

Capitaine, N., and Wallace, P., 2006, "High precision methods for locating the celestial intermediate pole and origin.", Astron. Astrophys., 450, 2, 855-872.

Capitaine, N., Folgueira, M., and Souchay, J., 2006, "Earth rotation based on the celestial coordinates of the celestial intermediate pole. I. The dynamical equations.", Astron. Astrophys., $445,1,347-360$.

Chao, B.F., Dehant, V., Gross, R.S., Plag, H.P., Ray, R.D., Salstein, D.A., van Dam, T., Van Hoolst, T., Watkins, M., Wilson, C.R., 2003, "The Global Geophysical Fluids Center (GGFC) of the International Earth Rotation Service.", in: Proc. IERS Workshop, Munich, Germany, November 2002, IERS Technical Notes, 30, Eds. B. Richter, W. Schwegmann, and W. Dick, 115-120.

Chao, B.F., Dehant, V., Gross, R.S., Plag, H.-P., Ray, R.D., Salstein, D.A., van Dam, T., Van Hoolst, T., Watkins, M.M., and Wilson, C.R., 2004, "The Global Geophysical Fluids Center (GGFC) of the International Earth Rotation and Reference Systems Service.", Proceedings of the IERS Workshop on Combination Research and Global Geophysical Fluids, Bavarian Academy of Sciences, Munich, Germany, 18-21 November 2002, Eds. B. Richter, W. Schwegmann, and W.R. Dick, IERS Technical Note No. 30, 115-120.

Chapront, J., and Francou, G., 2004, "The lunar libration. Comparisons between various models - A model fitted to LLR observations.", Proc. Journées Systèmes de Référence Spatio-Temporels 2004, ed. N. Capitaine, 216-221.

Chin, T.M., Gross, R.S., and Dickey, J.O., 2004, "Modeling and forecast of the polar motion excitation functions for short-term polar motion prediction.", J. Geodesy, DOI: 10.1007/s00190004-0411-4.

Chin, T.M., Gross, R.S., and Dickey, J.O., 2005, "Multi-reference evaluation of uncertainty in Earth orientation parameter measurements.", J. Geodesy, DOI: 10.1007/s00190-005-0439-0.

Coulot, D., Biancale, R., Berio, P., Gontier, A.-M., Loyer, S., Soudarin, L., Altamimi, Z., Lemoine, J.-M., Capitaine, N., Exertier, P., and Gambis, D., 2004, "Combination of space geodesy techniques for monitoring the kinematics of the Earth.", Proc. SF2A 2004, eds. F. Combes et al., EDP Sciences 2004, 19-22.

Débarbat, S., and Lerner, M.-P. , 2002, "Méridien, méridienne, de l'origine à nos jours, in Le calcul des longitudes.", Proc. of a coll. (Brest, France, May 2002) subtitled Un enjeu pour les mathématiques, l'astronomie, la mesure du temps et la navigation, Julien V. Ed., Press Univ. de Rennes, 19-35.

Débarbat, S., and Lerner, M.-P. , 2003, "La rotation de la Terre de l'Antiquité à l'aube du XXe siècle.", in: Proc. Jounées Systèmes de Référence Spatio-Temporels Astrometry from Ground and from Space (Bucharest, September 2002), Capitaine N. and Stavinschi M. Eds., 235-242.

Defraigne, P., Rivoldini, A., Van Hoolst, T., and Dehant, V., 2003, "Mars nutation resonance due to Free Inner Core Nutation.", J. Geophys. Res. (Planets), DOI: 10.1029/2003JE002145.

Dehant, V., Feissel-Vernier, M., de Viron, O., Ma, C., Yseboodt, M., and Bizouard, C., 2003a, "Remaining error sources in the nutation at the sub-milliarcsecond level.", J. Geophys. Res. (Solid Earth), 108(B5), 10.1029/2002JB001763.

Dehant, V., Van Hoolst, T., de Viron, O., Greff-Lefftz, M., Legros, H., and Defraigne, P., 2003b, "Can a solid inner core of Mars be detected from observations of polar motion and nutation of Mars?", J. Geophys. Res. (Planets), DOI: 10.1029/2003JE002140.

Dehant, V., Lognonné, P., Sotin, C., and the NetLander team, 2004, "Network science, NetLander: a European mission to study the planet Mars.", Planetary and Space Science, 52(11), 977-985. 
Dehant, V., de Viron, O., and Feissel-Vernier, M., 2004, "Investigation of nutation beyond the IAU2000 model.", Proc. IVS 3rd General Meeting, Ottawa, 9-12 fev. 2004. NASA/CP2004-212255.

Dehant, V., de Viron, O., and Greff-Lefftz M., 2005, "Atmospheric and oceanic excitation of the rotation of a three-layer Earth.", Astron. Astrophys., Vol. 438, 11491161, DOI: 10.1051/0004-6361:20042210.

Dehant, V., Feissel-Vernier, M., de Viron, O., Ma, C., Yseboodt, M., and Bizouard, C., 2003, "Remaining error sources in the nutation at the sub-milliarcsecond level.", JGRB, 108, 2275 .

de Viron, O., and Dehant, V., 2003, "Reliability of atmospheric torque for geodesy.", in: Proc. IERS Workshop, Munich, Germany, November 2002, IERS Technical Notes, 30, Eds. B. Richter, W. Schwegmann, and W. Dick, 125-126.

de Viron, O., and Dehant, V., 2003, "Test on the validity of the Atmospheric Torques on Earth computed from model outputs.", J. Geophys. Res., 108(B2), 10.1029/2001JB001196.

de Viron, O., Koot, L., and Dehant, V., 2004, "Polar motion models: The torque approach.", in Proc. of the Workshop on Forcing of polar motion in the Chandler Wobble frequency band: a contribution to understanding interannual climate variations, April 21-23 2004, Luxembourg, Cahier du Centre Européen de Géophysique et de Séismologie., Vol. 24, 9-14.

de Viron, O., and V. Dehant, 2004, "La rotation de la Terre.", Ciel et Terre, 120, 143-148.

de Viron, O., Salstein, D., Bizouard, C., and Fernandez, L., 2004, "Low frequency excitation of length-of-day and polar motion by the atmosphere.", J. Geophys. Res. (Solid Earth), 109, Issue B3, CiteID B03408.

Dickey, J. O., Marcus, S. L., and de Viron, O., 2003, "Coherent interannual and decadal variations in the atmosphere-ocean system.", Geophys. Res. Lett., 30(11), 1573, DOI: 10.1029/2002GL016763.

Duron, J., Rosenblatt, P., Yseboodt, M., Karatekin, O., Dehant, V., Van Hoolst, T., and Barriot, J.-P., 2003, "Joint estimation of Martian C20 and rotation variations from simultaneous geodetic measurements: Numerical simulations of a Network Science Experiment.", Geophys. Res. Letters, DOI: 10.1029/2003JL082003.

Feissel-Vernier, M., and Ma, C., 2002, "Radio source stability and the observation of precessionnutation.", Proc. IVS GM 2002 (N.R. Vandenberg and K. Baver eds.), NASA/CP-2002210002.

Feissel-Vernier, M., 2003, "Selecting stable extragalactic compact radio sources from the permanent astrogeodetic VLBI program.", Astron. Astrophys., 403, 105.

Feissel-Vernier, M., 2003, "Reference systems and frames: definition, maintenance, connections and influence.", Proc. Journées SF2A 2003, Combes et al. eds., EDP Sciences, les Ulis, France, 67-0

Feissel-Vernier, M., 2003, "VLBI astrogéodésique et sciences de la terre.", Ecole d'été du GDR géodésie-Géophysique Outils de géodésie pour la géophysique, Forcalquier, août 2003.

Feissel-Vernier, M. (ed.), 2004, "Report of the 2004 IDS Plenary Meeting.", on the IDS website.

Feissel-Vernier, M., Ray, J., Altamimi, A., Dehant, V., and de Viron, O., 2004, "VLBI and the Earth's rotation: Geophysical and geodetic challenges (Invited).”, IVS 3rd General Meeting, Ottawa, 9-12 fev. 2004. NASA/CP-2004-212255.

Feissel-Vernier, M., Ray, J., Altamimi, A., Dehant, V., and de Viron, O., 2004, "VLBI and the Earth's rotation: Geophysical and geodetic challenges.", IVS 3rd General Meeting, Ottawa, 9-12 fev. 2004, NASA/CP-2004-212255.

Feissel-Vernier, M., and Cognard, I, 2005, "Tying the dynamical and extragalactic reference frames via millisecond pulsars.", IERS Technical Note 34, eds. J. Souchay et M. FeisselVernier.

Feissel-Vernier, M., 2005, "Comments on the VLBI connection between celestial and terrestrial reference frames by means of sidereal time.", IERS Technical Note 34, eds. J. Souchay et M. Feissel-Vernier.

Feissel-Vernier, M., Ma C., Gontier A.-M., and Barache C., 2005, "Sidereal orientation of the Earth and stability of the VLBI celestial reference frame.", Astron. Astrophys. 438, 11411148.

Feissel-Vernier, M., Ma C., Gontier, A.-M., and Barache, C., 2006, "Analysis strategy issues for the maintenance of the ICRF axes.", Astron. Astrophys., 452, 3, 1107-1112. 
Fey, A.L., Ma, C., Arias, E.F., Charlot, P., Feissel-Vernier, M., Gontier, A.-M., Jacobs, C.S., Li, J., and MacMillan, D.S., 2004, "The International Celestial Reference Frame. Extension and Revision: Positions of 109 Additional Sources.", AJ, 127, 3587.

Folgueira, M., and Souchay, J., 2004, "Free polar motion of a triaxial and elastic body in Hamiltonian formalism: application to the Earth and Mars, Astron. Astrophys., 432, 1101-1113.

Folgueira, M., Capitaine, N., and Souchay, J., 2004, "The equations of the Earth's rotation in the framework of the IAU 2000 Resolutions.", Proc. Journées Systèmes de Référence Spatio-Temporels 2004, ed. N. Capitaine, 136-137.

Folgueira, M., and Souchay, J., 2005, "Free polar motion of a triaxial and elastic body in Hamiltonian formalism: Application to the Earth and Mars.", Astronomy and Astrophysics, 432, $3,1101-1113$.

Gambis, D., 2004, "Monitoring Earth Orientation at the IERS using space-geodetic observations.", J. of Geodesy, 78, 295-303.

Gambis, D., 2005, "Earth Orientation Monitoring, State-of-the-art and prospects.", Artificial Satellite, Journal of Planetary Geodesy.

Gambis, D., and Sillard, P., 2005, "Excitation of the Chandler Wobbler Amplitude by the El Nino Southern Oscillation process.", Cahiers du Centre Européen de Géodynamique et de Séismologie.

Gauchez, D., and Souchay, J., 2004, "Modelisation and effects of impacts with accretion.", soumis, Celestial Mechanics

Gontier, A.-M., and Feissel-Vernier, M., 2003, "Contribution of stable sources to ICRF improvements.", IAU XXV joint discussion 16.

Greiner-Mai, H., Jochmann, H., Barthelmes, F., and Ballani, L., 2003, "Possible influences of core processes on the Earth's rotation and the gravity field.", J. Geodyn. 36, 343-358

Gross, R.S., 2003a, "Laser ranging contributions to monitoring and interpreting Earth orientation changes.", in: 13th International Workshop on Laser Ranging: Proceedings from the Science Session and Full Proceedings CD-ROM, edited by R. Noomen, S. Klosko, C. Noll, and M. Pearlman, 107111, NASA-CP2003-212248.

Gross, R.S., 2003b, "CHAMP, mass displacements, and the Earths rotation.", in: First CHAMP Mission Results for Gravity, Magnetic and Atmospheric Studies, edited by Ch. Reigber, H. Lühr, and P. Schwintzer, 174179, Springer-Verlag, New York.

Gross, R.S., Fukumori, I., and Menemenlis, D., 2003, "Atmospheric and oceanic excitation of the Earths wobbles during 19802000.", J. Geophys. Res., 108(B8), 2370, DOI: 10.1029/2002JB002143.

Gross, R.S., 2004, "Angular momentum in the Earth system.", in: V Hotine-Marussi Symposium on Mathematical Geodesy, edited by F. Sanso, 274284, IAG Symposia vol. 127, SpringerVerlag, New York.

Gross, R.S., Fukumori, I., Menemenlis, D., and Gegout, P., 2004a, "Atmospheric and oceanic excitation of length-of-day variations during 19802000.", J. Geophys. Res., 109, B01406, DOI: $10.1029 / 2003 J B 002432$.

Gross, R.S., Blewitt, G., Clarke, P., and Lavallée, D., 2004b, "Degree-2 harmonics of the Earths mass load estimated from GPS and Earth rotation data.", Geophys. Res. Lett., 31, L07601, DOI: $10.1029 / 2004$ GL019589.

Gross, R.S., 2005a, "Oceanic excitation of polar motion: A review.", in: Forcing of Polar Motion in the Chandler Frequency Band: A Contribution to Understanding Interannual Climate Change, edited by H.-P. Plag, B. F. Chao, R. S. Gross, and T. van Dam, 89102, Cahiers du Centre Européen de Géodynamique et de Séismologie vol. 24, Luxembourg.

Gross, R.S., 2005b, "The observed period and Q of the Chandler wobble.", in: Forcing of Polar Motion in the Chandler Frequency Band: A Contribution to Understanding Interannual Climate Change, edited by H.-P. Plag, B. F. Chao, R. S. Gross, and T. van Dam, 3137, Cahiers du Centre Européen de Géodynamique et de Séismologie vol. 24, Luxembourg.

Gross, R.S., Fukumori, I., and Menemenlis, D., 2005, "Atmospheric and oceanic excitation of decadal-scale Earth orientation variations.", J. Geophys. Res., 110, B09405, DOI: 10.1029/2004JB003565.

Gubanov, V.S., Kozlova, I.A., Surkis, I.F., and Rusinov, J.L., 2002, "Processing of VLBI observations: software QUASAR, I-V.", Communications IAA RAS, No 141-145, in Russian. 
Gubanov, V.S., 2004, "Project: Global Analysis of 1979-2004 VLBI Data. Proc. Journées 2003, eds. A.Finkelstein and N.Capitaine, St.Petersburg, 22-25 Sep 2003, 3-10.

Gubanov, V.S., Rusinov, Yu. L., Surkis, I.F., Kurdubov, S.L., and Shabun, C.Ya., 2004, "Project: Global analysis of 1979-2004 VLBI Data.", in: IVS 2004 General Meeting Proceedings, eds. N.R. Vandenberg and K.D. Baver, NASA/CP-2004-212255, 315-319.

Guo, J.Y., Greiner-Mai, H., Ballani, L., Jochmann, H., and Shum, C. K., 2005a, "On the doublepeak spectrum of the Chandler wobble.", J. Geodesy 78, 654-659.

Guo, J.Y., Greiner-Mai, H., and Ballani, L., 2005b, "A spectral search for the inner core wobble in Earth's polar motion.", accepted by JGR B.

Haas, R., and Wünsch, J., 2005, "Sub-diurnal Earth rotation variations from the VLBI CONT02 campaign.", accepted by J. Geodyn.

Hengst, R., 2003, "Wavelet-Analysen ozeanischer Drehimpulszeitreihen.", Scientific Technical Report STR03/08, GFZ Potsdam, 85.

Huang, C.-L., and Liao, X.-H., 2003, "Comment on 'Representation of the elastic-gravitational excitation of a spherical Earth model by generalized spherical harmonics' by Phinney and Burridge.", Geophys. J. Int., 155(2), 669-678.

Huang, C.L., Dehant, V., and Liao, X.H., 2004, "The explicit scalar equations of infinitesimal elastic-gravitational motion in the rotating, slightly elliptical fluid outer core of the Earth.", Geophys. J. Int., 157, 831-837, DOI: 10.1111/j.1365-246X.2004.02238.x.

Huang, C.L., Dehant, V., Liao, X.H., de Viron, O., and Van Hoolst, T., 2005, "The coupling equations between the nutation and the geomagnetic field in GSH expansion.", In: Proceedings of Journées Systèmes de Référence Spatio-Temporels 2004 Fundamental Astronomy: New concepts and models for high accuracy observations, N. Capitaine ed., Observatoire de Paris, 20-22 September 2004, 88-93.

Johnson, T., and Price, D., 2003, "United States Groundwater Levels and NCEP Precipitation and the Effects of Groundwater on J2 Variability," EOS Trans. AGU, 84 (46), Fall meeting Suppl.

Johnson, T., 2004, "The Interannual Spectrum of the Atmosphere and Oceans," in Proc. of the Workshop on Forcing of Polar Motion in the Chandler Wobble Frequency Band: a Contribution to Understanding Interannual Climate Variations, April 21-23 2004, Luxembourg, Cahier du Centre Européen de Géophysique et de Séismologie., Vol. 24, 69-75.

Johnson, T., Luzum, B., and Ray, J., 2005a, "Improved Near-term UT1R Predictions Using Forecasts of Atmospheric Angular Momentum," J. Geodyn., 39 (3), 209-221.

Johnson, T., Kammeyer, P., Lambert, S., and Wooden, W., 2005b, "The Effects of the 2004 Sumatra Earthquake on Earth Rotation: A Comparison between Theory and Different Observational Techniques," EOS Trans.AGU, 86 (18), 2005 Joint Assembly, New Orleans, Louisiana.

Johnson, T., Kammeyer, P., and Wooden, W., 2005c, "The Effects of the 2004 Sumatra Earthquake on Earth Rotation: A Comparison between Theory and Observations," Geophysical Research Abstracts, 7, EGU General Assembly 2005 Meeting,Vienna, Austria.

Johnson, T., Chao, B., Au, A., and Cox, C., 2005d, "Global Land Hydrology and its Effects on Polar Motion," Geophysical Research Abstracts, 7, EGU General Assembly, Vienna, Austria.

Kalarus, M., Kosek, W., 2004, "Prediction of Earth orientation parameters by artificial neural networks.", Artificial Satellites - Journal of Planetary Geodesy, Vol. 39, No 2, 175-184.

Karatekin, O., Duron, J., Rosenblatt, P., Dehant, V., Van Hoolst, T., and Barriot, J.-P., 2005, "Martian Time-Varying Gravity and its Determination; Simulated Geodesy Experiments.", J. Geophys. Res., Planets, Vol. 110, DOI:10.1029/2004JE002378.

Kolaczek, B., Nastula, J., and Salstein, D., 2003, "El Nino-related variations in atmosphere-polar motion interaction.", Journal of Geodynamics, Special Issue: Earth rotation and episodic processes, Vol. 36 No. 3, 397-406.

Kolaczek, B., and Nastula, J., 2004, "Impact of the addition of the ocean to the atmospheric excitation of polar motion on variability of spectra and correlation with polar motion.", Proc. Journées Systèmes de réf érence Spatio-Temporels 2003: Astrometry, Geodynamics and Solar System Dynamics: from milliarcseconds to microarcseconds. St. Petersburg, Russia, 22-25 September, 2003, 150-154. 
Kosek, W., 2003, "Polar motion prediction by different methods in polar coordinate system.", Proc. of the Journées Systèmes de Réf érence Spatio-Temporels 2002, Bucarest, 25-28 Sep. 2002, 125-131.

Kosek, W., and Kalarus, M., 2003, "Time-frequency analysis and prediction of polar motion radius and angular motion.", Artificial Satellites - Journal of Planetary Geodesy Vol. 38, No.2, 41-54.

Kosek, W., Popinski, W., Schuh, H., and Schmidt, M., 2004, "Is there any frequency dependent time lag between atmospheric and geodetic excitation function?", In: Evolving Space Geodetic Techniques, Geowissenschaftliche Mitteilungen Nr. 69, eds. R. Weber, W. Schlüter, U. Schreiber, O. Titov, 86-92.

Kosek, W., 2004, "Possible excitation of the Chandler wobble by variable geophysical annual cycle.", Artificial Satellites - Journal of Planetary Geodesy, Vol. 39, No 2., 135-145.

Kosek, W., McCarthy, D.D., Johnson, T.J., and Kalarus, M., 2004, "Comparison of polar motion prediction results supplied by the IERS Sub-bureau for Rapid Service and Predictions and results of other prediction methods.", Proc. Journes Systèmes de Reference SpatioTemporels 2003, eds. A.Finkelstein and N.Capitaine, Inst. of Applied Astronomy of the Russian Acad. of Sciences, St. Petersburg, 164-169.

Kosek, W., 2005, "Excitation of the Chandler wobble by the geophysical annual cycle.", Proc. of the Workshop Forcing of polar motion in the Chandler frequency band: a contribution to under-standing interannual climate variations, eds. H.-P. Plag, B. Chao, R. Gross and T. van Dam, European Center for Geodynamics and Seismology, Luxembourg City, 121-126.

Kosek, W., Kalarus, M., Johnson, T.J., Wooden, W.H., McCarthy, D.D. and Popinski, W., 2005, "A comparison of LOD and UT1-UTC forecasts by different combination prediction techniques.", Artificial Satellites - Journal of Planetary Geodesy, Vol. 40, No. 2, 119-125.

Kostelecký, J., and Pesek, I. 2003, "Determination of station coordinates and EOP from combination of different techniques.", In: Richter B., Schwegmann W., Dick W.R. (Eds.): Proc. IERS Workshop on combination research and global geophysical fluids, , IERS Technical Note No. 30, BKG Frankfurt a.M., 214-215.

Kostelecký, J., and Pesek, I., 2006, "Determination of Earth orientation parameters and station coordinates from combination of IERS Cdata - internal comparisons." Proc. Journées Systèmes de Référence Spatio-Temporels 2005, 19-21 September, Warszaw.

Krasinsky, G.A., 2003, "Rotation of the deformable Earth with the viscous core.", Communications IAA RAS, No 157.

Krasinsky, G.A., 2006, "Numerical theory of rotation of the deformable Earth with the two-layer fluid core. Part 1: Mathematical model.", Celest. Mech. Dynam.l Astron., 96, 3-4, 169-217.

Krasinsky, G.A., and Vasilyev, M.V., 2006, "Numerical theory of rotation of the deformable Earth with the two-layer fluid core. Part 2: Fitting to VLBI data.", Celest. Mech. Dynam.l Astron., 96, 3-4, 219-237.

Lambert, S., 2004, "Influence of the Earth's rotation rate and deformations on precessionnutation," Proc. Journées Systèmes de Référence Spatio-Temporels 2003, ed. A. Finkelstein and N. Capitaine, 211-212.

Lambert, S., 2004, "Coupling between the Earth's rotation rate and precession-nutation," Proc. IAU XXV, Joint Discussion 16 : The International Celestial Reference System, Maintenance and Future Realizations, July 2003, eds. R. Gaume, D.D. McCarthy, J. Souchay.

Lambert, S., 2004, "Non-linear terms in the non-rigid Earths .", Proc. Journées Systèmes de Référence Spatio-Temporels 2004, ed. N. Capitaine, 144-145

Lambert, S., and Capitaine, N., 2004, "Effects of Zonal Deformations and the Earth's Rotation Rate Variations on Precession-Nutation," Astron. Astrophys., 428, 255-260.

Lambert, S., 2005, "Second-order terms in the Earth's nutation," Journées Systèmes de Référence Spatio-Temporels 2004, pp 144-145.

Lambert, S., and Mathews, P.M., 2006, "Second-order torque on the tidal redistribution and the Earth's rotation," Astron. Astrophys., 453, 1, 363-369.

Lerner, M.-P., and Débarbat, S., 2004, "La lune et sa rotation de l'Antiquité au XVIIe siècle.", in: Proc. Journées 2003 Systèmes de Référence Spatio-Temporels Astrometry, Geodynamics and Solar System Dynamics: From milliarcseconds to microarseconds (St-Petersburg, September 2003), Finkelstein A. and Capitaine N. Eds., 128-137. 
Li, Z.X., Li, H., Li, Y., and Han, Y., 2005, "Non-tidal variations in the deflection of the vertical at Beijing Observatory", Journal of Geodesy, 78, 588-593, DOI: 10.1007/s00190-004-0421-2

Li, Z.X., 2006, "A study on earthquake-related geoid deformations at Beijing-Tangshan during 1987-1998.", Journal of Geodesy.

Malkin, Z., 2002, "A Comparison of the VLBI Nutation Series with IAU2000 Model.", In.: IVS 2002 General Meeting Proc., eds. N. R. Vandenberg, K. D. Baver, NASA/CP-2002-210002, 335-339.

Malkin, Z., 2002, "A Comparison of the VLBI Nutation Series With Model.", In.: IERS Technical Note No 29, Proc. IERS Workshop on the Implementation of the New IAA Resolutions, BKG, 107-108.

Malkin, Z., 2002, "A Comparative Analysis of the VLBI Nutation Series.", In: Proc. Journées 2001: Influence of geophysics, time and space reference frames on Earth rotation studies, Brussels, Belgium, Sep 24-26, 2001, Ed. N. Capitaine, 34-39.

Malkin, Z., 2003a, "On systematic differences in individual solutions and IERS products.", eds. B. Richter, W. Schwegmann, and W. Dick, in: Proc. IERS Workshop on the Combination Research and Global Geophysical Fluids, Munich, Germany, November 18-21, 2002, IERS Technical Note No 30, BKG, Frankfurt am Main, 87-88.

Malkin, Z., 2003b, "Some problems in the IERS products from user's point of view.", in: Proc. IERS Workshop on the Combination Research and Global Geophysical Fluids, Munich, Germany, November 18-21, 2002, eds. B. Richter, W. Schwegmann, and W. Dick, IERS Technical Note No 30, BKG, Frankfurt am Main, 207-208.

Malkin, Z., and Terentev, D., 2003a, "Investigation of the Parameters of the Free Core Nutation from VLBI data.", Communications IAA RAS, No 149.

Malkin, Z., and Terentev, D., 2003b, "Preliminary analysis of the Free Core Nutation from VLBI data.", in: Proc. 16th Working Meeting on European VLBI for Geodesy and Astrometry, Leipzig, Germany, 9-10 May 2003, 227-235.

Malkin, Z., 2004a, "A New Free Core Nutation Model with Variable Amplitude and Period.", in: IVS 2004 General Meeting Proc., eds. N. R. Vandenberg and K. D. Baver, NASA/CP2004-212255, 388-392.

Malkin, Z., 2004b, "Comparison of VLBI nutation series with the IAU2000A model.", in: Proc. Journées 2003, eds. A. Finkelstein and N. Capitaine, 24-31.

Malkin, Z.M., Skurikhina, E.A., and Gayazov, I.S., 2005, IAA EOP Service, All-Russian conference Positioning, Timing and Navigation- 2005, St. Petersburg, 2005, in press, in Russian.

Marcus, S.L., de Viron, O., and Dickey, J. O., 2004, "Atmospheric contributions to Earth nutation: Geodetic constraints and limitations of the torque approach.", J. Atmos. Sciences, 61(3), 352356.

McCarthy, D., and Petit, G. (eds.), 2004, IERS Conventions (2003), IERS Technical Note No. 32, Verlag des Bundesamts für Kartographie und Geodsie, Frankfurt, Germany.

McCarthy, D., 2005, "Free Core Nutation.", in: Proc. Journées Systèmes de Référence SpatioTemporels 2004, 101-105.

Nastula, J., Salstein D.A., and Ponte R.M., 2003, "Empirical patterns of variability in atmospheric and oceanic excitation of polar motion.", Journal of Geodynamics, Special Issue: Earth rotation and episodic processes, 36, 3, 383-396.

Nastula, J., Salstein, D. A., and Kolaczek, B., 2003, "Time variable atmospheric and oceanic signals in excitation functions of polar motion.", Proceedings of the IERS Workshop on Combination Research and Global Geophysical Fluids, Bavarian Academy of Sciences, Munich, Germany, CD Proceedings, 127-130.

Nastula, J., and Kolaczek, B., 2005, "Studies of regional atmospheric pressure excitation function of polar motion.", Proc. Journées Systèmes de Référence Spatio-Temporels 2004 Fundamental astronomy: New concepts and models for high accuracy observations, Paris Observatory, Paris France, 20-22 September 2004, 146-147.

Nastula, J., and Gambis, D., 2004, "Assessment of quality of polar motion series derived from space-geodetic techniques.", Proc. Journées Systèmes de Référence Spatio-Temporels 2004 Fundamental astronomy: New concepts and models for high accuracy observations, Paris Observatory, Paris France, 20-22 September 2004, 148-149.

Nastula, J., Kolaczek, B., Weber, R., Böhm, J., and Schuh, H., 2004, "High Resolution Earth Rotation Parameters Determined During the CONT02 Campaign Observations.", In: 
Proceedings IVS 2004 General Meeting, ed. by N.R. Vandenberg and K.D. Baver, NASA/CP-2004-212255, 408-412.

Nastula, J., 2005, "Polar motion excitation from atmospheric-oceanic angular momentum.", Proceedings of the Earth Rotation and Satellite Geodesy from Astrometry to GNSS, Warsaw, September, 18-19, 2003, Artificial Satellites, Vol. 40, No 1, 43-59.

Nastula, J., and Kolaczek, B., 2005, "Analysis of hydrological excitation of polar motion.", Proceedings of the Chandler Wobble Workshop, Luxemburg, 21-23 August 2003, 149-154.

Nastula, J., Salstein, D. A., and Kolaczek, B., 2005, "Excitations of polar motion from an Ensemble of Global Atmospheric Models Proceedings of the International Association of Geodesy.", in: Proc. A window on the future of Geodesy, Sapporo Japan, June30-July 11, 2003, Springer-Verlag Berlin Heidelberg 2005, F. Sanso (eds.), 597-600.

Panafidina, N., and Malkin, Z., 2004, "Computation of a homogeneous coordinate time series for European GPS stations by reprocessing of the weekly EPN solutions.", in: EUREF Publication No 13, eds J.A. Torres and H. Hornik, BKG, Frankfurt am Main, 2004, 423427.

Panafidina, N., Skurikhina, E., and Sokolova, Y., 2004, "GPS and VLBI baseline length variations.", in: Proc. Journées 2003, Eds. A. Finkelstein and N.Capitaine, 89-90.

Pesek, I., and Kostelecký, J., 2005, "Simultaneous determination of Earth orientation parameters and station coordinates from combination of results of different observation techniques.", submitted to Studia Geoph. et Geod.

Petrov, L., and Ma, C., 2003, "Study of harmonic site position variations determined by very long baseline interferometry.", J. Geophys. Res, 108(B4), DOI: 10.1029/2002JB001801.

Petrov, L., and Boy, J.-P., 2004, "Study of the atmospheric pressure loading signal in very long baseline interferometry observations.", J. Geophys. Res., 109, B03405, DOI: 10.1029/2003JB002500.

Ponsar, S., Dehant, V., and Van Hoolst, T., 2003, "Electromagnetic core-mantle coupling.", in: Proc. IERS Workshop, Munich, Germany, November 2002, IERS Technical Notes, 30, Eds. B. Richter, W. Schwegmann, and W. Dick, 216-219.

Popinski, W., Kosek, W., Schuh, H., and Schmidt, M., 2002, "Comparison of two wavelet transform coherence and cross-covariance functions applied on polar motion and atmospheric excitation.", Studia geophysica geodaetica, Vol. 46, 455-468.

Ron, C., Capitaine, N. and Vondrák, J., 2005, "A precession study based on the astrometric series and the combined astrometric catalogue EOC-2.", in: N. Capitaine (Ed.) Proc. Journées Systèmes de Référence Spatio-Temporels 2004, 20-22 September 2004, Paris, 110-114.

Rosenblatt, P., Marty, J.C., Perosanz, F., Barriot, J.P., Van Hoolst, T., and Dehant, V., 2004, "Numerical simulations of a Mars geodesy network experiment: Effect of orbiter angular momentum desaturation on Mars' rotation estimation.", Planetary and Space Science, 52(11), 965-975.

Schuh, H., Ulrich, M., Egger, D., Müller, J., and Schwegmann, W., 2002, "Prediction of Earth orientation parameters by artificial neural networks.", Journal of Geodesy, 76, 247-258.

Schuh, H., Varga, P., Seitz, T., Böhm, J., Weber, R., Mentes, G., Zavoti, J., and Westerhaus, M., 2003, "Sub-semidiurnal variations of the EOP observed by space geodesy compared with other Geophysical phenomena.", Proceedings Journées 2001, Brussels, ed. by N. Capitaine, Observatoire de Paris, UMR 8630/CNRS, 95-97.

Schuh, H., Dill, R., Greiner-Mai, A., Kutterer, H., Müller, J., Nothnagel, A., Richter, B., Rothacher, M., Schreiber, U., and Soffel, M., 2003, "Erdrotation und globale dynamische Prozesse,", Mitteilungen des Bundesamtes für Kartographie und Geodsie, Band 32, Frankfurt a. M. ISSN 1436-3445, ISBN 3-89888-883-5.

Schuh, H., 2004, "Erdrotation und globale dynamische Prozesse., promet, Jahrgang 30, Heft 3, Deutscher Wetterdienst, 153-160.

Schuh, H., Boehm, J., Weber, R., Nastula, J., and Kolaczek, B., 2004, "High resolution Earth rotation parameters determined during the CONT02 Campaign.", IVS 2004 General Meeting Proceedings, ed. by N.R. Vandenberg and K.D. Baver, NASA/CP-2004-212255, 408-412.

Schmitz-Hübsch, H., and Schuh, H., 2003, "Seasonal and Short-Period Fluctuations of Earth Rotation Investigated by Wavelet Analysis.", In: Geodesy The Challenge of the Third Millennium, ed. by E.W. Grafarend, F.W. Krumm and V.S. Schwarze, Springer-Verlag, 125-134. 
Sevilla, M.J., 2003, "Actualización de cálculos astronómicos.", Serie: cursos y seminarios del Instituto de Astronoma y Geodesia (CSIC-UCM), Madrid, N. 8, ISBN: 84-87488-08-0.

Shirai, T, Fukushima, T., and Malkin, Z. 2005, "Detection of phase disturbances of free core nutation of the Earth and their concurrence with geomagnetic jerks.", Earth Planets Space, $57(2), 151-155$.

Sidorenkov, N.S., 2003a, "Influence of the atmospheric tides on the Earth rotation.", Celestial Mechanics and Dynamical Astronomy, Vol. 87, No. 12, 27-38.

Sidorenkov, N.S., 2003b, "Influence of the atmospheric and oceanic circulation on the plate tectonics.", In Journées 2003. Astrometry, Geodynamics and Solar System Dynamics: from milliarcseconds to microarcseconds, St. Petersburg, September 22-25, Ed. A. Finkelstein and N. Capitaine, 225-230.

Sidorenkov, N.S., 2003c, "Changes in the Antarctic ice sheet mass and the instability of the Earth's rotation over the last 110 years.", International Association of Geodesy Symposia, Vol.127, 339-346.

Sidorenkov, N.S., 2004, "Instability of the Earths Rotation.", Herald of the Russian Academy of Sciences, Vol. 74, No. 4, 402409.

Soffel, M., Klioner, S., Petit, G., Bretagnon, P., Capitaine, N., et al., 2003, "Explanatory supplement for the IAU'2000 resolutions on relativity.", AJ 126, 2687-2706.

Sokolova, Yu., 2005, "Influence of the early VLBI observations on the ICRF stability.", Proc. Journées 2004, (in press).

Souchay, J., Kinoshita, H., Nakai, H., and Roux, S., 2003, "A precise modeling of Eros 433 rotation.", Icarus, 166, 285-296.

Souchay, J., Folgueira, M., and Bouquillon, S., 2003, "Effects of the Triaxiality on the Rotation of Celestial Bodies: Application to the Earth, Mars and Eros.", Earth Moon \& Planets, 93, $2,107-144$.

Souchay, J., Ma, C., and Feissel-Vernier, M., 2003, "Celestial reference frame issues.", Proc. IERS Workshop on combination research and global geophysical flruids, Munich, 18-21 November 2002. IERS Technical Note No 30.

Souchay, J., 2004, "Characteristics of EROS 433 rotation.", in Proc. Journées Systèmes de référence2003, St. Petersburg, 18-20 September 20003, eds. A. Finkelstein and N. Capitaine, 263-268.

Souchay, J., and Bouquillon, S., 2004, "The high frequencies variations of Erosrotation.", Astron. \& Astroph. (accepté juin 2004).

Souchay, J., and Bouquillon, S., 2004, "Rotation of the Earth, Mars and asterods: comparative study of models and data quality.", Proc. SF2A 2004, eds. F. Combes et al., EDP Sciences 2004, 43-46.

Souchay, J., and Gaume, R., 2004, "Activities of the ICRS Product Center of the IERS.", Proc. Journées Systèmes de Référence Spatio-Temporels 2004, ed. N. Capitaine, in press.

Souchay, J., Folgueira, M., and Bouquillon, S., 2004, "Effect of the triaxiality on the rotation of celestial bodies: application to the Earth, Mars and Eros.", Earth, Moon and Planets, 93, Issue 2, 107-144.

Souchay, J., and Folgueira, M., 2005, "Numerical Approach to the Free Rotation of Celestial Bodies.", Joint Discussion 16: The International Celestial Reference System, Maintenance and Future Realizations, eds. R. Gaume, D. D. McCarthy, J. Souchay, in press.

Souchay, J., and Feissel-Vernier, M., (eds.), 2005, "The International Celestial Reference System and Frame.", IERS Technical Note 34, BKG Frankfurt.

Souchay, J., Gontier, A.M., and Barache, C., 2006, "Cross-identifications and astro-photometric comparisons of the ICRF with recent catalogs of quasars.", Astron. Astrophys., 453, 2, 743-749.

Stavinschi, J. Souchay, 2003, "Some correlations between earthquakes and earth tides" Acta Geodetica \& Geophysicae, 38, 77-92.

Titov, O., and Tregoning, P., 2005, "Effect of post-seismic deformation on earth orientation parameter estimates from VLBI observations: a case of study at Gilcreek, Alaska.", Journal of Geodesy, 79, 196-202.

Van Hoolst, T., Dehant, V., Roosbeek, F., and Lognonné, P., 2003, "Tidally induced surface displacements, external potential variations, and gravity variations on Mars.", Icarus, 161, 281-296, DOI: 10.1016/S0019-1035(2)00045-2. 
Varga, P., Engels, J., and Grafarend, E.W., 2004, "Temporal variations of the polar moment of inertia and the second-degree geopotential.", Journal of Geodesy, 78, 3, 187-191.

Verhoeven, O., Rivoldini, A., Vacher, P., Mocquet, A., Choblet, G., Menvielle, M., Dehant, V., Van Hoolst, T., Sleewaegen, J., Barriot, J.-P., and Lognonné, P., 2005, "Interior structure of terrestrial planets. I. Modelling Mars' mantle and its electromagnetic, geodetic and seismic properties.", J. Geophys. Res. (Planets), 110(E4), E04009, DOI: 10.1029/2004JE002271.

Vondrák J., and ?epek A., 2000, "Combined smoothing method and its use in combining Earth orientation parameters measured by space techniques.", Astron. Astrophys. Suppl. Ser. 147, 347-359.

Vondrák, J., Ron, C., and Weber, R. 2003, "Combined VLBI/GPS series of precession-nutation and comparison with IAU 2000 model.", Astron. Astrophys. 397, 771-776.

Vondrák, J., and Ron, C., 2005a, "Combined astrometric catalogue EOC-2 an improved reference frame for long-term Earth orientation studies.", in: N. Capitaine (Ed.) Proc. Journées 2004 Systèmes de Référence Spatio-Temporels , 20-22 September 2004, Paris, 210-215.

Vondrák, J., and Ron, C., 2005b, "The great Chandler wobble change in 1923-1940 re-visited.", in: H. P. Plag, B. Chao, R. Gross and T. van Dam (Eds.) Proc. of the Workshop on Forcing of polar motion in the Chandler Wobble frequency band: a contribution to understanding interannual climate variations, April 21-23 2004, Luxembourg, Cahiers du Centre Européen de Géodynamique et de Séismologie, Vol. 24, 39-47.

Vondrák, J., Weber, R., and Ron, C., 2005, "Free core nutation: direct observations and resonance effects.", accepted by Astron. Astrophys.

Wallace, P., and Capitaine, N., 2006, "Precession-nutation procedures consistent with IAU 2006 resolutions.", Astron. Astrophys., 459, 3, 981-985.

Wooden, W., Johnson, T, Carter, M., and Myers, A., 2004, "Near Real-time IERS Products," Journées Systèmes de Référence Spatio-Temporels 2003, 160-163.

Wooden, W., Johnson, T., Kammeyer, P., Carter, M., and Myers, A., 2005, "Determination and Prediction of UT1 at the IERS Rapid Service/Prediction Center," Journées Systèmes de Référence Spatio-Temporels 2004, 260-263.

Wu, Bin, Schuh H., Peng, Bibo, 2003, "New treatment of tidal braking of Earth rotation.", Journal of Geodynamics, 36, 515-521.

Yseboodt, M., Barriot, J.-P., and Dehant, V., 2003, "Analytical modeling of the Doppler tracking between a lander and a Mars orbiter in term of rotational dynamics.", J. Geophys. Res. 108(E7), 5076, DOI: 10.1029/2003JE002045. 